\title{
Starvation resistance in larvae of a semiterrestrial crab, Sesarma curacaoense (Decapoda: Grapsidae)
}

\author{
Klaus Anger \\ Biologische Anstalt Helgoland, Meeresstation, D-27483 Helgoland, Germany
}

Received 27 July 1994; revision received 10 October 1994; accepted 26 October 1994

\begin{abstract}
Starvation resistance in the larvae of a semiterrestrial grapsid crab, Sesarma curacaoense De Man, 1892, was studied by point-of-no-return (PNR) and point-of-reserve-saturation (PRS) experiments. $S$. curacaoense shows an abbreviated larval development (only two zoeal stages) and a high degree of lecithotrophy. In complete absence of food, larval development is possible from hatching to the megalopa stage. Thus, no PNR or PRS can be given for individual zoeal stages of this species. However, late effects of early starvation indicate that lecithotrophy is only facultative in $S$. curacaoense zoeae: food is not essential but will be eaten when available. The endotrophic potential decreases from the first to the last larval stage: while the zoea $I$ is entirely independent of external food sources, the zoea II shows increasingly delayed development after increased periods of initial food deprivation, and the megalopa can develop independent of food only if the preceding zoeal stages were fed continuously. Besides ontogenetic changes, significant variability was observed also in starvation resistance of larvae originating from different females. In an experiment with a particularly starvation-resistant hatch, development in the zoea II was accelerated during continuous lack of food or when starvation followed brief initial feeding periods. This effect was interpreted as a mechanism which should be specific to facultative lecithotrophy: starvation may induce a change in energy partitioning, from a preference for growth (uptake and accumulation of additional energy reserves) to accelerated development (mobilization of internal reserves, rapid termination of the planktonic larval phase). Enhanced starvation resistance in $S$. curacaoense zoeae compared with that in most planktotrophic marine decapod larvae is considered an adaptation that allows for retention of the larvae within a nutritionally unstable environment where the adult populations live. These ontogenetic traits corroborate the assumption that $S$. curacaoense may be the closest relative of an ancestral Sesarma species from which adaptive radiation of endemic Jamaican freshwater and terrestrial crabs began.
\end{abstract}

Keywords: Abbreviated development; Semiterrestrial; Starvation resistance 


\section{Introduction}

The larval development of marine grapsid crabs normally comprises $\geq 4$ planktotrophic zoeal stages and a megalopa; some species, however, which have invaded already or are in transition to terrestrial and freshwater environments, show an abbreviation of the zoeal phase and a tendency toward lecithotrophy (review: Rabalais \& Gore, 1985; Hartnoll, 1988). These traits are particularly conspicuous in a group of closely related Sesarminae (mostly Sesarma species, including also the bromeliad crab, Metopaulias depressus), which are endemic to the island of Jamaica (Hartnoll, 1964; Abele, 1992). They all are believed to have evolved from a common coastal marine ancestor. According to morphological criteria, this hypothetical ancestor should have been very similar to an extant semiterrestrial species living in mangrove swamps, Sesarma curacaoense (Hartnoll, 1964).

Hence, one may expect to find preadaptations in the life cycle of this presumed ancestral form, facilitating the invasion of limnic and terrestrial habitats: namely, abbreviated larval development, high tolerance of the larvae to extreme physical conditions, large quantities of yolk in the early stages, and an unusual degree of independence from planktonic food. Recent experimental studies (Anger \& Schultze, 1995) have shown that the larval development of $S$. curacaoense is in fact abbreviated, with only two zoeal stages and a megalopa, and all stages tolerate a wide range of salinities (Schuh \& Schultze, unpubl.). Unusually high amounts of organic materials in freshly hatched zoeae as well as particularly low growth rates indicate that degradation of internal energy reserves (yolk) plays a major role in its zoeal development (Anger \& Schultze, 1995). This suggests that the larvae should be more tolerant of temporary lack of food compared with most planktotrophic marine decapod crustacean larvae.

This hypothesis was tested in the present investigation, examining the starvation resistance of $S$. curacaoense larvae by point-of-no-return (PNR) and point-of-reservesaturation (PRS) experiments in the laboratory (Anger \& Dawirs, 1981). Comparable studies were previously available for only three other grapsid crab species, $S$. reticulatum Say, 1817, Armases (Sesarma) cinereum Bosc, 1802, and A. (Sesarma) miersii Rathbun, 1897 (Staton \& Sulkin, 1991; Anger, 1995a), and a number of marine decapods belonging to other families (Anger et al., 1981; McConaugha, 1985; Anger, 1987).

\section{Materials and methods}

Ovigerous $S$. curacaoense females were collected in August 1992 in coastal mangrove swamps in Jamaica and transported alive to the Helgoland Marine Biological Station. Since preliminary observations (Schuh, unpubl.) suggested that slightly diluted rather than full-strength seawater was preferred by this species, the crabs were maintained at $25 \%$ salinity. Temperature was kept constant at $24^{\circ} \mathrm{C}$, with a $12: 12 \mathrm{~h}$ light:dark cycle. The larvae were later reared under the same conditions.

Two types of experiments were carried out with the larvae, following the procedures described by Anger \& Dawirs (1981): (1) point-of-no-return (PNR), (2) point-of-reservesaturation (PRS) experiments (experimental design shown in Fig. 3a). Both the PNR 
and PRS are indices of larval starvation tolerance: the PNR is the average time of initial food deprivation that will cause irreversible damage, i.e. not allowing for recovery after later re-feeding; the PRS is the minimum time of initial feeding after which a later food-independent development to the next stage is possible (Anger, 1987). In PNR experiments, freshly hatched zoea I larvae were in parallel subexperiments (treatments) initially starved for different lengths of time. Thereafter, they were fed freshly hatched Artemia sp. (San Francisco Bay Brand ${ }^{\mathrm{TM}}$ ) nauplii. In PRS treatments, the larvae were fed initially for differential periods and then deprived of food. In both types of experiments, there were continuously fed and starved control groups (FC, SC; Fig. 3a). Water and food (where applicable) were changed daily. The larvae were kept individually in glass vials (diameter: $2.5 \mathrm{~cm}$; height: $6 \mathrm{~cm}$ ) with $\approx 25 \mathrm{ml}$ of seawater.

The first hatch comprised only few larvae $(<100)$, so that only a preliminary experiment with few treatments and a low number of individuals in each treatment was possible. This series (PNR type) will be referred to as "experiment \# 1/1992" (or "Exp. \# 1/92"). Fifteen larvae each were distributed among fed and starved controls (FC, $\mathrm{SC}$ ), and two groups that were initially starved for 1 or 2 days (S1, S2). The second experiment ("Exp. \#2/92") was started shortly thereafter using another hatch. Since more larvae were available, six PNR treatments (S1-S6) as well as FC and SC groups with 25 larvae each were included in this experiment.

The third experiment ("Exp. 93") was conducted in April 1993 at the University of the West Indies Discovery Bay Marine Laboratory (DMBL), Jamaica. Temperature was kept constant at $25^{\circ} \mathrm{C}$. Salinity was not reduced in this experiment, since a study by Schuh \& Schultze (unpubl.) had shown that no significant effects occurred in between about $20-40 \%$ o $S$, neither in survival nor in development rate; ambient seawater salinity varied between $32-35 \%$. The experiment was comprised of five PNR (S1-S5; see above) and an equal number of PRS treatments (F1-F5), as well as SC and FC groups; all larvae ( 25 per treatment) originated from the same hatch. The experiments were checked twice daily for moults and mortality, at 12-h intervals ( 0800 and 2000).

Statistical analysis of survival and development data follwed standard methods (Sokal \& Rohlf, 1981; Sachs, 1984). Since goodness-of-fit $G$-tests showed that development data within treatments sometimes deviated significantly from a normal distribution, non-parametric tests were used for their analysis. The Kruskal-Wallis $H$-test was employed in multiple comparison of mean values (non-parametric ANOVA), and the Mann-Whitney $U$-test for pairwise comparisons. The results of an $H$-test were in one case scrutinized by an extended median test (Sachs, 1984; p. 237). Contingency tables (survival data) were analyzed following a stepwise test procedure described by Sokal \& Rohlf (1981, p. 728; $G$-tests for homogeneity). Trends within a series of PNR or PRS experiments were tested with a linear least-square regression model. Slopes of different regression lines were compared with a $t$-statistic for data sets with unequal variances and a low number of observations (Sachs, 1984; p. 341). 


\section{Results}

\subsection{PNR experiments}

Originally, these experiments were designed to quantify the PNR of the first zoeal stage in three different hatches. However, practically all larvae survived independently of food to the zoea II, most of them even to the megalopa stage (Figs. 1-3), so that the original PNR concept (Anger \& Dawirs, 1981) could not be applied here. Due to high endotrophic potential of the larvae, the PNR shifted out of the first zoeal stage, at least to the end of the zoea II or the beginning of the megalopa moult cycle. Survival in the first zoeal stage was in all experiments not influenced by temporary or continuous starvation. In Exp. \# 1/1992 and 1993, the zoea I had no mortality at all (Figs. 1a and 3b) and in Exp. \# 2/1992 only very little (Fig. 2a; maximum, with two individuals $=8 \%$, in the fed control (FC) group).

The zoea II showed in the first and third experiment still almost no mortality regardless of feeding or starvation. In the second hatch (Exp. \#2/92), initial starvation periods up to 6 days (S6) had no effects on zoea II survival $(G=2.0$, n.s.); however, significantly lower survival was in this experiment observed in the continuously starved
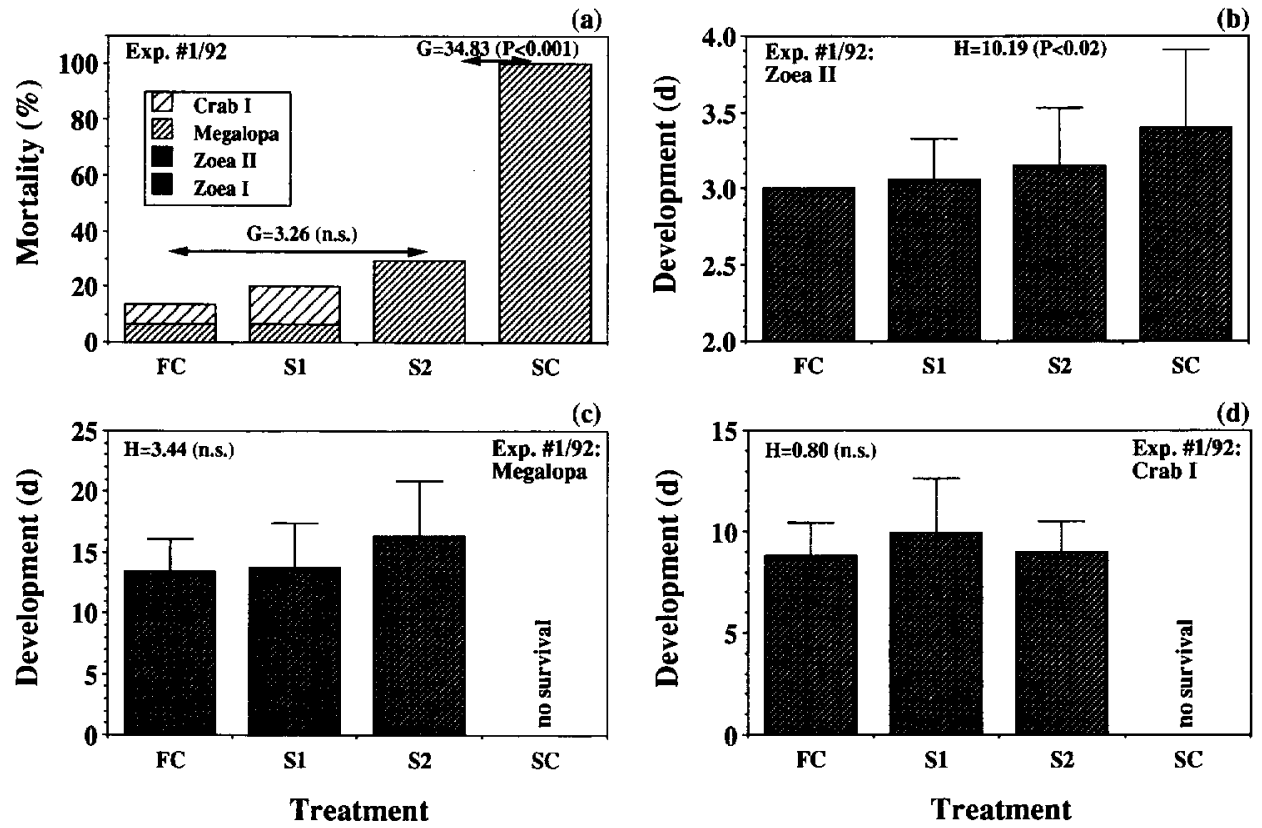

Fig. 1. Sesarma curacaoense: Exp. \# $1 / 1992$. (a) Mortality ( $\%$; with initially $n=15$ larvae per treatment); (b-d) duration of development $(\bar{x} \pm$ SD; (d) in the zoea II, megalopa and first juvenile crab stage, respectively. Treatments: continuously fed or starved control groups (FC, SC); experimental groups with one or two days of initial starvation (S1, S2). $H:$ Kruskal-Wallis statistic for multiple comparison of mean values; $G$ : statistic of test for homogeneity in contingency data; $p$ : probability of error for rejecting the null hypotheses; $n . s$.: not significant $(p>0.05)$. 

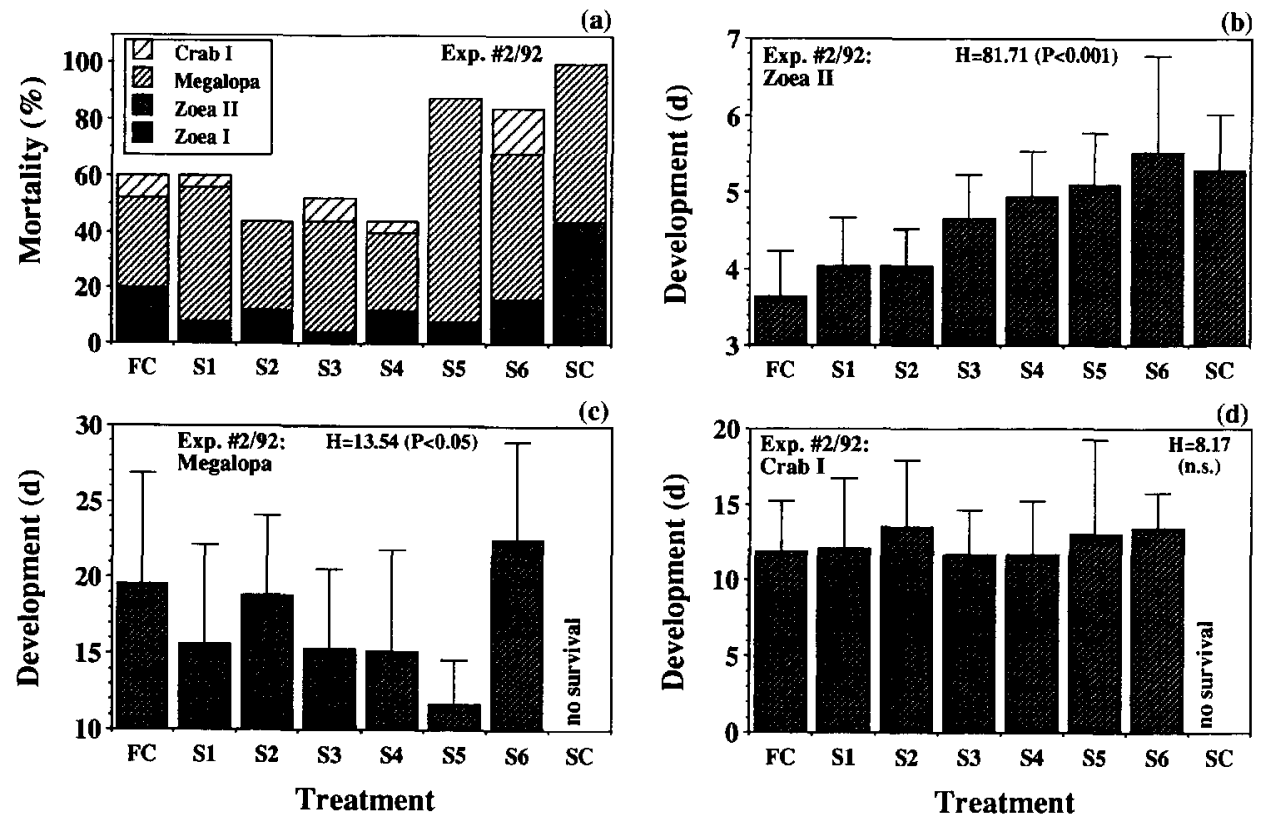

Fig. 2. Sesarma curacaoense: Exp. \# 2/1992; with initially $n=25$ larvae per treatment. For further explanation see Fig. 1.

control (SC) group (Fig. $2 \mathrm{a} ; G=18.6, p<0.01$ ). These results indicate a lower starvation resistance in the "Exp. \#2/92" larvae compared with those in the other two hatches.

Most larvae successfully reached the megalopa stage regardless of treatment, but not a single megalopa survived in a continuously starved control group through metamorphosis to the first juvenile crab. Thus, the potential for endotrophic development decreased after hatching, and yolk reserves from the eggs were depleted in the final larval stage. Survival of the megalopa in treatments with temporary initial starvation varied significantly in Exp. \#2/1992 (S5 and SC groups with higher mortality; $G=18.6$, $p<0.01$, in all other treatments no significant heterogeneity) and in Exp. 1993 (Fig. 3b). However, these patterns of variation appeared to be haphazard and cannot be explained exclusively by the duration of previous starvation treatments. Mortality of first-stage juvenile crabs (ascertained only in the two 1992 experiments) also did not show a clear relationship with previous periods of food deprivation.

Particularly weak starvation resistance in the second hatch ("Exp. \#2/92") compared with the two others was indicated not only by higher mortality rates in all larval stages (Fig. 2a; cf. Fig. 1a and Fig. 3b), but also by comparing survival patterns in the three SC groups directly with each other (Fig. 4a). Median survival time was significantly different not only in a multiple ( $H$-test), but also in pairwise next-neighbour comparisons ( $U$-tests; all $p<0.001$ ), with clearly lowest survival time in the "Exp. \# 2/92" hatch. 

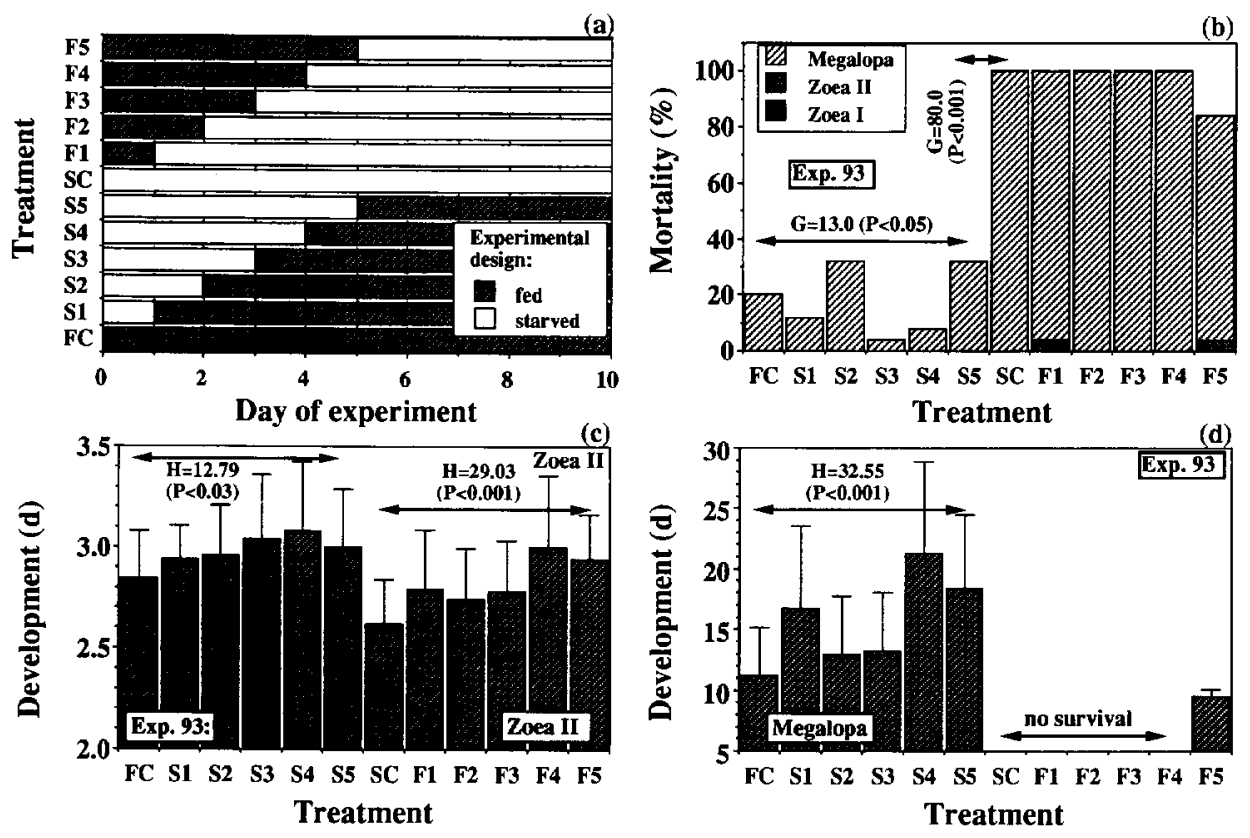

Fig. 3. Sesarma curacaoense: Exp. 1993. (a) Experimental design in treatments of temporary feeding (F1F5) or starvation (S1-S5); (b) mortality $(\%$; with initially $n=25$ larvae per treatment). For further explanation see Fig. 1.

Duration of development varied significantly in the zoea I stage between different hatches (Fig. 4c), but not between the experimental treatments. Longest development duration was mostly observed in "Exp. \#2/92" (zoea I, megalopa), or in both 1992 hatches (zoea II), whereas shortest development was consistently found in the 1993 larvae (Figs. 4c,d). Variability among hatches from different females was in all stages statistically significant $(H$-test; $p<0.001)$.

While duration of development was in the zoea I not influenced by initial lack of food, that in the zoea II tended in all three experiments to increase with increasing duration of the starvation period (Figs. 1b, 2b and 3c). As the only exception, the SC group in the 1993 experiment (Fig. 3c) had a significantly shorter development in the zoea II compared not only with initial starvation treatments (S1-S5) but also with the FC. This pattern will be discussed below.

When the three different hatches are compared, the same tendency as in survival time of SC groups (Fig. 4a) may be seen also in the delay of zoea II development after initial starvation (Fig. 4b): again, the "Exp. \# 2/92" larvae showed the strongest response to starvation. In all three experiments, a positive linear relationship between the duration of initial starvation and later delay of zoea II development was found (all correlation and regression coefficients significantly different from zero; $p<0.05$ ). The slope of the regression line was significantly larger in the "Exp. \# 2/92" experiment compared with either of the two others ( $p<0.001$; no significant difference between "Exp. \# 1/92" and “Exp. 93"). 

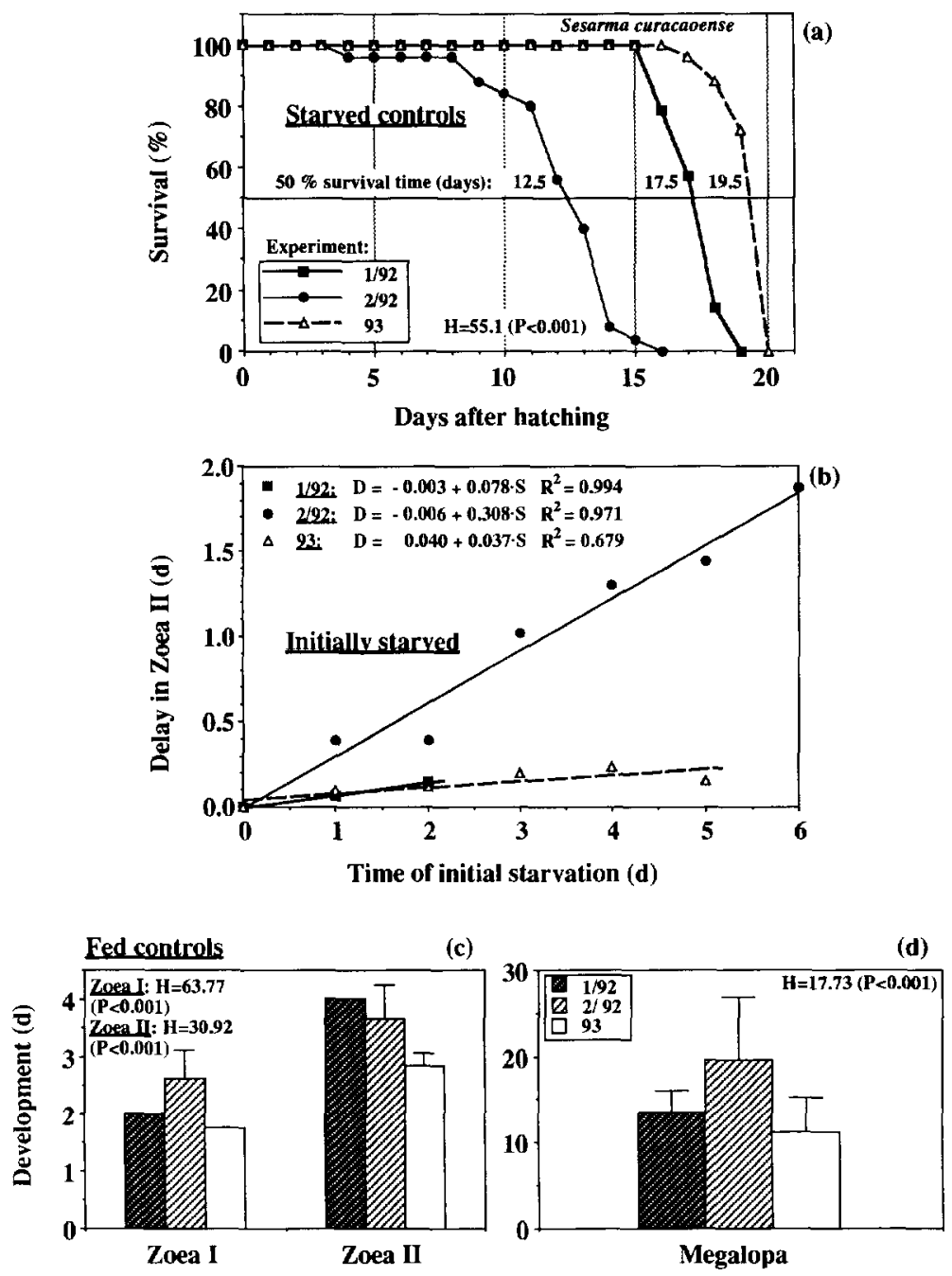

Fig. 4. Sesarma curacaoense: comparison of three different hatches (Exp. \# 1/92, 2/92, 93). (a) Survival time (days) in the continuously starved control groups, $\mathrm{SC}$; (b) delay (D; d) of development in the zoea II after differential times of initial starvation, $S$ (treatment SC not included here); (c,d) duration of development $(\bar{x} \pm \mathrm{SD})$ in continuously fed control groups, FC. $R^{2}$ : coefficient of determination. For further explanation see Fig. 1 .

In the 1993 experiment, significant variation in megalopa development was indicated by an $H$-test, but these results indicate no clear relationship to initial starvation (Fig. 3d); a slight increasing trend with increasing starvation time in "Exp. \#1/92" (Fig. 1c) was not statistically significant. Hence, effects of early starvation periods on megalopa development must be considered weak or absent. Likewise, no significant effect was observed in the first juvenile stage (Fig. 1d). 


\subsection{PRS experiments}

An attempt to quantify the PRS is given only in the 1993 experiment (Fig. 3). Again, the feeding regime had no influence on survival or development duration of the zoea I, but only in later stages. Although the "Exp. 93" hatch was particularly starvationresistant, food had to be available initially for at least 5 days to allow at least some larvae (four individuals out of 24 that had survived to the megalopa) to reach metamorphosis to the first juvenile crab stage in later absence of food (Figs. 3b-d). It is remarkable that in all survivors of the F5 treatment, starvation had commenced $\approx 12 \mathrm{~h}$ before moulting to the megalopa began, that is, these larvae were able to develop in complete absence of food from the late zoea II through the entire megalopa stage, and eventually to metamorphose successfully to the first juvenile. These results show that both zoeal stages do not have a PRS in its original definition, because this critical point shifted backward into the embryonic phase.

While mortality in the two zoeal stages was not influenced by PRS treatments (Fig. 3b), development duration of the zoea II showed significant variation $(p<0.001$;

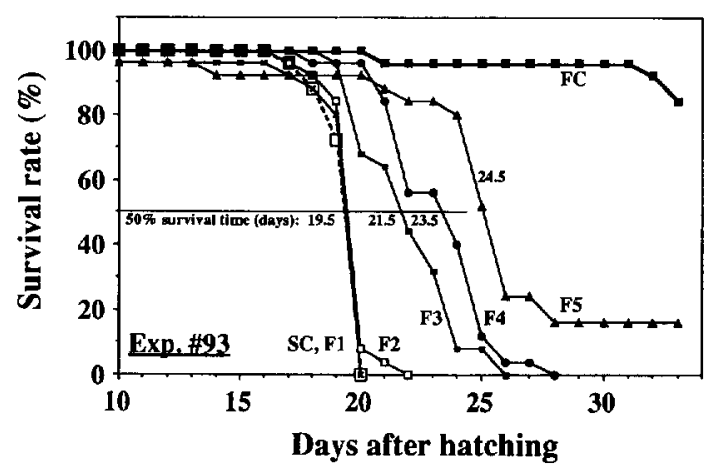

(a)

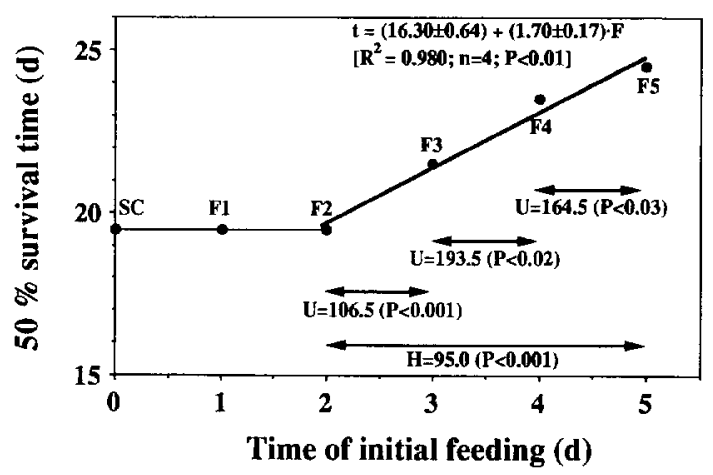

(b)

Fig. 5. Sesarma curacaoense: Exp. 1993. (a) Survival time after differential initial periods of feeding followed by starvation; numbers near $50 \%$ line: median time of survival (d); (b) median values [ $t$; from graph (a)] plotted against duration of feeding periods, $F$; $U$ : Mann-Whitney statistic for pairwise comparisons of mean values. For further explanation see Figs. 1 and 3. 
Fig. 3c). Surprisingly, it did not decrease but showed an increasing tendency with increasing length of initial feeding. This seemingly paradoxical result will be discussed below.

After the PNR experiments had shown that feeding is not essential during the zoeal stages of $S$. curacaoense, the PRS experiments also addressed the question of whether very early feeding has any importance at all for larval development in this species. Since almost all larvae in the PRS treatments died in the megalopa stage (Fig. 3b), the duration of survival was used as a measure of possible effects of earlier feeding. Mortality patterns in the PRS treatments are shown in Fig. 5a. One can see that the SC, F1 and F2 groups had almost identical survival curves, whereas in all other treatments the larvae tended to survive longer with increasingly longer feeding periods.

When the median survival times are plotted against the duration of initial feeding (Fig. 5b), no effect (identical values) can be seen in the treatments without, with 1 , or with 2 days of food availability. Highly significant effects of feeding, however, were found in groups receiving food for 3-5 days. Not only was the overall variation in treatments F2-F5 highly significant ( $H$-test), but also pairwise comparisons of next neighbours ( $U$-tests; Fig. 5 b). This increasing trend in median survival time with increasing duration of feeding periods $>2$ days can be described with a linear regression, indicating the proportionality of this effect. A slope of 1.7 suggests that each additional day of feeding prolonged the average time of survival during later starvation by $>1$ day (Fig. 5b).

\section{Discussion}

Compared with most other grapsid crab species where larval development is known (for review see Rabalais \& Gore, 1985, Table 2), S. curacaoense shows an abbreviation of the zoeal phase. With only two zoeal stages, its development resembles that in two closely related terrestrial grapsids, Geosesarma perracae (Lam, 1969) and Metopaulias depressus (Hartnoll, 1964; Anger \& Schuh, 1992), and in a fiddler crab, Uca subcylindrica (Rabalais \& Cameron, 1983, 1985). These species have lecithotrophic zoeae, and a feeding megalopa stage.

Enhanced starvation resistance, or low "nutritional vulnerability" (Sulkin, 1978), is shown also by $S$. curacaoense zoeae. They are able to develop from hatching to the megalopa stage in complete absence of food. However, early starvation periods not affecting the first stage consistently caused a slower development in the zoea II. Such late consequences of early lack of food indicate that the zoeae are feeding stages. On the other hand, these delayed effects differed from the reponse patterns that are known from planktotrophic marine decapod larvae; developmental delay is typically found within the same moult cycle where starvation occurred (Anger et al., 1981; McConaugha, 1985; Anger, 1987). Thus, the endotrophic potential in $S$. curacaoense is exceeded by that in the fully lecithotrophic zoeae of $U$. subcylindrica, $M$. depressus, and $G$. perracae, but it is greater than in most planktotrophic marine decapod larvae. Only the semiterrestrial species $S$. reticulatum and Armases (Sesarma) miersii are known to show similar tendencies of abbreviated and partially lecithotrophic zoeal develop- 
ment as $S$. curacaoense, but to a lesser extent (Anger et al., 1981; Staton \& Sulkin, 1991; Anger, 1995a; Schuh \& Diesel, 1995).

In spite of being feeding stages, the zoeae of $S$. curacaoense are in principle independent of external food supply (facultative lecithotrophy). The zoea I reveals initially large quantities of yolk (indicated by an unusually high percentage carbon content of its biomass; Anger \& Schultze, 1995), but when food is available, the larvae will accumulate additional energy reserves. This opportunistic developmental strategy (termed "facultative planktotrophy" by Vance, 1973) should be advantageous under nutritionally unpredictable conditions: while a high endotrophic potential (normally a trait of non-feeding larvae) ensures the survival of early stages, the capability to grow (a trait of feeding larvae) should enhance the starvation resistance of later stages, increase the size at metamorphosis, and probably improve the performance of early juveniles (Emlet, 1986).

Food availability becomes increasingly important in later larval stages of $S$. curacaoense. While the zoea I was not significantly affected by absence of food, the zoea II showed under continued starvation a delayed development and, in a nutritionally more vulnerable hatch, also enhanced mortality; the megalopa was able to pass its entire moult cycle without food only if the preceding zoeal stages had been fed continuously. Thus, the zoeal stages can rely on decreasing albeit high yolk reserves, whereas the megalopa depends, at least indirectly, on exogenous energy sources. This ontogenetically decreasing endotrophic potential (or increasing feeding activity) is indicated also by effects observed in PRS experiments: brief food availability during only the zoea I stage did not significantly increase the duration of survival during later starvation, whereas feeding through parts of the zoea II moult cycle (although still not sufficient for later food-independent development through metamorphosis) had such a delaying effect on mortality (Fig. 5).

An ontogenetically decreasing potential for endotrophic development has been observed also in $A$. miersii larvae (Anger, 1995a), accompanied by an increasing tendency in their cannibalistic activity (Anger, 1995b). Thus, cannibalism appears to be a nutritional buffer (comparable with nurse eggs) in small, food-limited breeding habitats such as supratidal rock pools (Anger, 1995b). Since $S$. curacaoense may also develop in a food-limited habitat (presumably, within the adult burrows, or in other small water reservoirs in the mangrove zone), cannibalism, at least by megalopae on zoea larvae, might have a similar significance in development and population dynamics of this species.

Besides ontogenetic changes, starvation resistance showed also a great deal of variability among $S$. curacaoense larvae originating from different females. This cannot be attributed to slightly different rearing conditions in our 1992 and 1993 experiments carried out at Helgoland and in Jamaica, respectively (differences: $1^{\circ} \mathrm{C}$ in temperature, $\approx 8 \%$ in salinity). One 1992 hatch ("Exp. \# 1/92") and that of 1993 gave very similar results (despite different conditions), whereas the response patterns in the two 1992 hatches (with identical rearing conditions) differed significantly from each other. Thus, variability in the duration of individual larval stages (Figs. 4c,d) should be based also on genetic or maternal factors, associated with a large variability in the amount of yolk material in freshly hatched larvae (Anger, unpubl. data). Similar variability had also 
been found in the initial biomass of bromeliad crab, $M$. depressus, larvae (Anger \& Schuh, 1992).

In the 1993 experiment, the continuously starved (SC) zoea II showed a significantly shorter development duration than all initially starved groups (S1-S5) and even compared with the fed control (FC; Fig. 3c). This effect is interpreted as a switching mechanism in energy partitioning between two normally synchronized, but in principle independent processes: development and growth. In starved larvae, lack of food may induce a switch from growth (oriented toward accumulation of additional exogenous energy reserves) to accelerated morphogenesis (based on mobilization of endogenous reserves, oriented toward rapid termination of the planktonic larval phase).

Presumably, this effect was observed only in the 1993 experiment because these larvae were particularly resistant against starvation, i.e. they were equipped with a large enough quantity of yolk to allow for an accelerated endotrophic development. This is in contrast to planktotrophic marine decapod larvae with lesser energy reserves, which must decelerate their metabolic and developmental processes under starvation stress; this strategy is oriented toward energy saving under poor nutritional conditions (dormancy). In $S$. curacaoense larvae with relatively little starvation resistance (1992 hatches), these typical patterns of developmental delay after starvation were also observed, but only in a later stage.

This presumed switching effect could explain also why the duration of zoea II development in "Exp. 93" larvae showed a decreasing tendency with decreasing duration of initial food availability (F1-F5; Fig. 3c): the earlier feeding ceased, the earlier the onset of starvation may have induced a switch from growth to accelerated endotrophic development. In treatments where food became available only after initial periods of starvation (PNR experiments; Fig. 3c), re-feeding may have caused a reversal, i.e. from accelerated development to preference for growth. In this case, retarded development would allow for a greater accumulation of exogenous energy reserves and thus, improve the chances of survival and development under possible later starvation.

The same presumed switching mechanism in energy allocation probably exists also in the larvae of another Jamaican grapsid crab species that shows facultative lecithotrophy, A. miersii (Anger, 1995a). In general, this opportunistic bioenergetic strategy should be specific to "nutritionally flexible" (sensu Sulkin \& van Heukelem, 1980), i.e. to partially lecithotrophic larvae. It resembles the "developmental plasticity" that has been found in other marine invertebrate larvae as a response to variable food concentrations (Strathman et al., 1992); it may be a step in the frequently occurring evolutionary loss of the feeding larval phase (see Strathman, 1985, for discussion).

Transitional environments such as the semi-arid mangrove swamps where $S$. curacaoense lives are during dry periods characterized by high salinities and temperatures, alternating with sudden climatic changes during heavy rainfall or cool weather (Rabalais \& Cameron, 1985). Hence, both physical conditions and plankton production should be unstable, and larval development of crabs jeopardized by those unpredictable conditions, selecting for abbreviation and lecithotrophy of larval development (Rabalais \& Gore, 1985). The semiterrestrial crab S. curacaoense shows life-cycle characteristics that are transitional between those of coastal marine and freshwater or terrestrial species. On the other hand, $S$. curacaoense does not enter freshwater (Hartnoll, 1964, 
1965), and it coexists with marine grapsids that have small eggs and presumably a planktotrophic larval development with a higher number of zoeal stages: Grapsus grapsus, Pachygrapsus gracilis, P. transversus, Cyclograpsus integer, Goniopsis cruentata, Aratus pisonii, Armases ricordi, A. angustipes (Hartnoll, 1965; Chace \& Hobbs, 1969; Abele, 1992). This shows that the special ontogenetic traits found in $S$. curacaoense cannot be essential for the existence of crab species in this type of habitat.

In general, two alternative life-cycle strategies are possible in harsh transitional environments. Most decapod species with a marine planktotrophic type of larval development avoid such unfavourable conditions by following an "export strategy", i.e. females or larvae migrate to coastal marine waters, and only postmetamorphic stages later return from the sea to settle in the adult habitat (e.g. Cristy \& Stancyk, 1982; Morgan, 1987). The larvae of $S$. curacaoense, in contrast, are well adapted to tolerate salinity stress (Schuh \& Schultze, unpubl.), as well as temporary lack of food. These ontogenetic adaptations make $S$. curacaoense more independent of the sea than coexisting coastal species, suggesting that it follows a "retention strategy" (Sandifer, 1973), i.e. it may pass its entire larval development in the same unpredictable marginal environment as where the adult populations live.

These life-cycle traits may be considered preadaptations that could already have occurred in an ancestral curacaoense-like Sesarma species, allowing for radiation into adjacent freshwater and terrestrial environments. Thus, they support Hartnoll's (1964) conclusion (drawn from adult male pleopod morphology) that $S$. curacaoense should be the closest relative of the ancestral Sesarma, from which adaptive radiation of endemic Jamaican freshwater and terrestrial crabs began. In addition, the present observations suggest that there may be a great deal of genetic variability in the endotrophic potential of $S$. curacaoense larvae. In the ancestral Sesarma species, this might have facilitated differential selection under variable local conditions and hence, speciation in different niches of the transitional zone between sea and land.

\section{Acknowledgements}

I would like to thank the staff of the DBML, Jamaica, for kind hospitality, Miss M. Schuh for transporting live crabs from Jamaica to Germany and for helping in an experiment at the DBML, Dr. R. Diesel for financial and logistic support, Miss U. Süsens and B. Bartels for technical assistance in rearing experiments at Helgoland, Miss U. Alexander for typing the manuscript, and Miss D. Schreiber for correcting the English. This research was funded by the Deutsche Forschungsgemeinschaft (DFG, Bonn; Grant no.: Di 476/1-1 conferred to Dr. Diesel). This is contribution 570 from the DBML.

\section{References}

Abele, L.G., 1992. A review of the grapsid crab genus Sesarma (Crustacea: Decapoda: Grapsidae) in America, with the description of a new genus. Smithson. Contrib. Zool, Vol. 527, pp. 1-60.

Anger, K., 1987. The $\mathrm{D}_{0}$ threshold: a critical point in the larval development of decapod crustaceans. J. Exp. Mar. Biol. Ecol, Vol. 108, pp. 15-30. 
Anger, K., 1995a. Developmental biology of Armases miersii (Grapsidae), a crab breeding in supratidal rock pools. I. Facultative lecithotrophy of larval stages. Mar. Ecol. Prog. Ser., Vol. 117, pp. 75-81.

Anger, K., 1995b. Developmental biology of Armases miersii (Grapsidae), a crab breeding in supratidal rock pools. II. Food-limitation in the nursery habitat and larval cannibalism. Mar. Ecol. Prog. Ser., Vol. 117, pp. 83-89.

Anger, K. \& R.R. Dawirs, 1981. Influence of starvation on the larval development of Hyas araneus (Decapoda, Majidae). Helgol. Wiss. Meeresunters., Vol. 34, pp. 287-311.

Anger, K. \& M. Schuh, 1992. Bioenergetics of abbreviated larval development in the bromeliad crab, Metopaulias depressus (Decapoda: Grapsidae). Comp. Biochem. Physiol., Vol. 103A, pp. 507-518.

Anger, K. \& K. Schultze, 1995. Elemental composition (CHN), growth, and exuvial loss in the larval stages of two semiterrestrial crabs, Sesarma curacaoense and Armases miersii (Decapoda: Grapsidae). Comp. Biochem. Physiol. (in press).

Anger, K., R.R. Dawirs, V. Anger \& J.D. Costlow, 1981. Effects of early starvation periods on zoeal development of brachyuran crabs. Biol. Bull., Vol. 161, pp. 199-212.

Chace, F.A. \& H.H. Hobbs, 1969. The freshwater and terrestrial decapod crustaceans of the West Indies with special reference to Dominica. Bull. Nat. Mus. U.S. Wash., Vol. 292, pp. 298.

Christy, J.H. \& S.E. Stancyk, 1982. Timing of larval production and flux of invertebrate larvae in a wellmixed estuary. In, Estuarine comparisons, edited by V.S. Kennedy, Academic Press, pp. 489-503.

Emlet, R.B., 1986. Facultative planktotrophy in the tropical echinoid Clypeaster rosaceus (Linnaeus) and a comparison with obligate planktotrophy in Clypeaster subdepressus (Gray) (Clypeasteroida: Echinoidea). J. Exp. Mar. Biol. Ecol., Vol. 95, pp. 183-202.

Hartnoll, R.G., 1964. The freshwater grapsid crabs of Jamaica. Proc. Linn. Soc. Lond., Vol. 175, pp. 145-169.

Hartnoll, R.G., 1965. Notes on the marine grapsid crabs of Jamaica. Proc. Linn. Soc. Lond., Vol. 176, pp. 113-147.

Hartnoll, R.G. 1988. Evolution, systematics, and geographical distribution. In, Biology of the land crabs, edited by W.W. Burggren \& B.R. McMahon, Cambridge University Press, New York, pp. 6-54.

Lam, S.C., 1969. Abbreviated development of non-marine crab, Sesarma (Geosesarma) perracae (Brachyura; Grapsidae), from Singapore. J. Zool. Lond., Vol. 158, pp. 357-370.

McConaugha, J.R., 1985. Nutrition and larval growth. In, Larval growth, edited by A.M. Wenner, Balkema Press, Rotterdam/Boston, pp. 127-154.

Morgan, S.G., 1987. Adaptive significance of hatching rhythms and dispersal patterns of estuarine crab larvae: avoidance of physiological stress by larval export? J. Exp. Mar. Biol. Ecol., Vol. 113, pp. 71-78.

Rabalais, N.N. \& J.N. Cameron, 1983. Abbreviated development of Uca subcylindrica (Stimpson, 1859) (Crustacea, Decapoda, Ocypodidae) reared in the laboratory. J. Crust. Biol., Vol. 3, pp. 519-541.

Rabalais, N.N. \& J.N. Cameron, 1985. The effects of factors important in semi-arid environments on the early development of Uca subcylindrica. Biol. Bull., Vol. 168, pp. 147-160.

Rabalais, N.N.\& R.H. Gore, 1985. Abbreviated development in Decapods. In, Larval growth, edited by A.M. Wenner, Balkema Press, Rotterdam/Boston, pp. 67-126.

Sachs, L., 1984. Angewandte statistik. Springer-Verlag, sixth edition, $552 \mathrm{pp}$.

Sandifer, P.A., 1973. Distribution and abundance of decapod crustacean larvae in the York River estuary and adjacent lower Chesapeake Bay, Virginia, 1968-1969. Chesapeake Sci., Vol. 14, pp. 235-257.

Schuh, M. \& R. Diesel, 1995. The effects of salinity, temperature, and starvation on the larval development of Armases ( = Sesarma) miersii (Decapoda, Grapsidae). J. Crust. Biol. (in press).

Sokal, R.R. \& F.J. Rohlf, 1981. Biometry. The principles and practice of statistics in Biological Research. W.H. Freeman \& Co., San Francisco, 859 pp.

Staton, J.L. \& S.D. Sulkin, 1991. Nutritional requirements and starvation resistance in larvae of the brachyuran crabs Sesarma cinereum (Bosc) and S. reticulatum (Say). J. Exp. Mar. Biol. Ecol., Vol. 152, pp. 271284.

Strathmann, R.R., 1985. Feeding and nonfeeding larval development and life-history evolution in marine invertebrates. Annu. Rev. Ecol. Syst., Vol. 16, pp. 339-361.

Strathmann, R.R., L. Fenaux \& M.F. Strathmann, 1992. Heterochronic developmental plasticity in larval sea urchins and its implications for evolution of nonfeeding larvae. Evolution, Vol. 46, pp. 972-986.

Sulkin, S.D., 1978. Nutritional requirements during larval development of the Portunid crab, Callinectes sapidus Rathbun. J. Exp. Mar. Biol. Ecol., Vol. 34, pp. 29-41. 
Sulkin, S.D. \& van Heukelem, W.F., 1980. Ecological and evolutionary significance of nutritional flexibility in planktotrophic larvae of the deep sea red crab Geryon quinquedens and the stone crab Menippe mercenaria. Mar. Ecol. Prog. Ser., Vol. 2, pp. 91-95.

Vance, R.R., 1973. On reproductive strategies in marine benthic invertebrates. Am. Nat., Vol. 107, pp. 339352. 